\title{
Implementasi Overclocking Pada Processor Intel Core i5- 2500k Untuk Meningkatkan Kinerja Komputer
}

\author{
Rizki Dwi Utama ${ }^{1}$, Didi Juardi ${ }^{2}$, Nono Heryana ${ }^{3}$ \\ ${ }^{1,2,3)}$ Program Studi Teknik Informatika, Universitas Singaperbangsa Karawang \\ Email: ${ }^{1}$ rizki.16195@student.unsika.ac.id, ${ }^{2}$ didi.juardi@staff.unsika.ac.id, ${ }^{3}$ nono@staff.unsika.ac.id
}

(Naskah masuk: 18 November 2019, diterima untuk diterbitkan: 2 Desember 2019)

\begin{abstract}
ABSTRAK
Processor merupakan suatu komponen pada komputer yang berfungsi sebagai otak dari komputer. Processor memiliki kecepatan frekuensi yang berpengaruh pada kinerja komputer. Semakin tinggi kecepatan frekuensinya maka kinerja komputer akan semakin baik. Ada suatu cara untuk meningkatkan kecepatan frekuensi pada processor, yaitu dengan overclocking. Overclocking processor dapat meningkatkan kinerja pada komputer. Selain meningkatkan kecepatan frekuensi pada processor, overclocking juga berdampak pada meningkatnya suhu dan konsumsi daya pada processor. Penelitian ini bertujuan untuk menerapkan cara-cara dalam melakukan overclock pada processor dan mengetahui perubahan kinerja dan kondisi pada processor yang telah di-overclock. Implementasinya yaitu dengan melakukan eksperimen secara langsung dengan menggunakan komputer.
\end{abstract}

Kata kunci: Daya, Kinerja, Overclocking, Processor, Suhu

\begin{abstract}
Processor is a component on a computer that functions as the brain of a computer. The processor has a frequency speed that affects computer performance. The higher the frequency speed, the better the computer's performance will be. There is a way to increase the frequency speed on the processor, by overclocking. Overclocking a processor can improve performance on a computer. In addition to increasing the frequency speed on the processor, overclocking also has an impact on increasing the temperature and power consumption of the processor. This study aims to apply ways to overclock the processor and determine changes in performance and conditions on the processor that has been overclocked. The implementation is by conducting experiments directly using a computer.
\end{abstract}

Keywords: Power, Performance, Overclocking, Processor, Temperature

\section{PENDAHULUAN}

Processor telah berkembang dari generasi ke generasi dengan berbagai perkembangan fitur dan semakin banyak tipe-tipe processor dengan kecepatan yang berbeda-beda. Processor pertama yang digunakan untuk komputer adalah Intel 4004 yang telah dirilis pada tanggal 15 November 1971 dan disebut sebagai microprocessor. Microprocessor tersebut hanya memiliki clock speed $740 \mathrm{kHz}$ (kilohertz). Setelah itu dimulailah perkembangan tipe-tipe processor hingga muncul tipe i3, i5, i7, dan i9. Seiring berkembangnya teknologi komputer, cara apapun bisa dilakukan supaya bisa meningkatkan kinerja pada suatu processor, termasuk dalam melakukan overclocking. Sebetulnya tidak ada catatan yang pasti terkait bagaimana awal mula 
overclocking. Overclocking sendiri sudah ada sejak sekitar tahun ' 80 -an.

Menurut (Indriyatmoko and Arief, 2015) Overclock adalah proses menjalankan komputer potensial dengan pada tingkat clock yang lebih tinggi (siklus clock yang lebih tinggi setiap detiknya) dari yang sudah diatur oleh produsen komputer tersebut. Menurut (Lutfi and Prasetyo, 2017) tujuan utama overclock bukanlah mencari speed yang setinggi- tingginya dari clock processor, tetapi mencari kecepatan stabil tertinggi dari sebuah sistem dari processor.

Di zaman sekarang ini overclock sendiri tujuannya tidak hanya menghemat biaya dan meningkatkan kecepatan. Teknik overclock yang sekarang bisa bertujuan untuk uji kemampuan pada processor. Bisa juga untuk uji ketelitian dan keberanian dalam menanggung resiko dan bahkan sekarang sudah dilombakan secara internasional. Para pengguna komputer pun bisa melakukan overclock secara mandiri dan mereka bisa meningkatkan berbagai macam teknik overclock yang bervariasi.

Tujuan dari penelitian ini adalah :

1) Mengetahui peningkatan kinerja dari processor yang telah di-overclock.

2) Menganalisa perubahan suhu dan daya dari processor yang telah dioverclock.

\section{LANDASAN TEORI}

\subsection{Penelitian Sebelumnya}

1) Penelitian pertama yang dilakukan oleh (Indriyatmoko and Arief, 2015) dari jurusan Teknik Informatika di STMIK AMIKOM Yogyakarta, mereka melakukan perbandingan pada processor dalam melakukan proses rendering antara default setting dan overclock setting.
2) Penelitian kedua yang dilakukan oleh (Nurrachma and Syafrizal, 2016) dari STMIK AMIKOM Yogyakarta, mereka melakukan extreme overclock pada processor Pentium G3258 dengan menggunakan sistem phase change untuk mendinginkan processor sampai dibawah titik beku.

3) Penelitian ketiga yang dilakukan oleh (Fahrizal, Alfanz and Sakti, 2016) mereka menggunakan processor i54670K untuk di-overclock. Mereka berhasil meningkatkan kinerja processor sebesar $17 \%$, suhu yang dihasilkan naik sebesar $27 \%$ dan output daya meningkat sebesar $34 \%$ dari frekuensi default.

4) Penelitian keempat yang dilakukan oleh (Lutfi and Prasetyo, 2017) dari jurusan Teknik Informatika di STMIK BINA PATRIA Magelang. Mereka melakukan eksperimen overclocking dengan menggunakan processor Intel i7-2600k dan berhasil meningkatkan core speed sebesar 4$4,5 \mathrm{GHz}$. Pengujian yang mereka lakukan adalah benchmark sintesis, real-world, suhu dan daya.

5) Penelitian kelima yang dilakukan oleh (Azhar and H, 2019) dari jurusan Teknik Elektro di Universitas Muhammadiyah Makassar. Eksperimen yang mereka lakukan menggunakan AMD AthlonTM II X2 250. Pengujian dilakukan dengan benchmark sintesis menggunakan software Super PI dan berhasil menaikkan frekuensi sebesar 3.750 $\mathrm{MHz}$. 


\subsection{Processor}

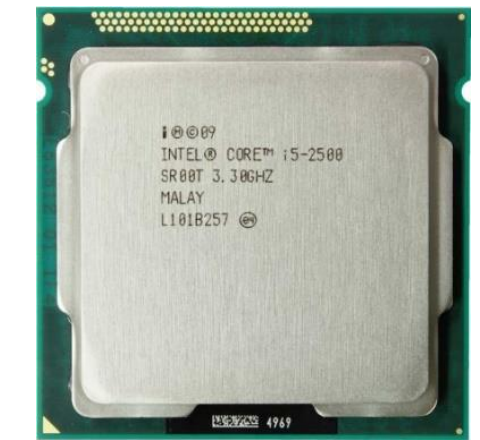

Gambar 1. Bentuk fisik processor

(Sumber: versus.com)

Menurut (Sari, 2014) processor sering disebut sebagai otak dan pusat pengendali komputer yang didukung oleh komponen lainnya. Processor adalah sebuah IC (Integrated Circuit) yang mengontrol keseluruhan jalannya sebuah sistem komputer dan digunakan sebagai pusat atau otak dari komputer yang berfungsi untuk melakukan perhitungan dan menjalankan tugas. Processor adalah perangkat terpenting dalam komputer, yaitu tenaga pelaksana sebuah eksekusi perintah atau program.

\subsection{Overclock}

Menurut (Nurrachma and Syafrizal, 2016) Overclock adalah sebuah proses untuk meningkatkan kecepatan komputer melebihi kecepatan setandar dari pabrikan. Sebenarnya komputer tidak dijalankan dalam kondisi kemampuan penuhnya, dan masih bisa ditingkatkan lagi. Hanya saja tidak diset seperti itu untuk menghindari hal-hal yang tidak diinginkan, berupa kerusakan hardware atau software. Untuk bisa melakukan overclocking, pertama harus terlebih dahulu mengetahui dan mengenal komponen-komponen komputer dan cara kerjanya. Karena komponen inilah yang akan dioptimalkan.

\section{METODE PENELITIAN}

Penelitian eksperimen adalah penelitian yang berusaha mencari pengaruh variable tertentu terhadap variabel lain dengan kontrol yang ketat (Sedarmayanti and Hidayat, 2002). Menurut Yatim Riyanto dalam (Zuriah, 2006) penelitian eksperimen merupakan penelitian yang sistematis, logis, dan teliti di dalam melakukan kontrol terhadap kondisi. (Sugiyono, 2018) menambahkan penelitian eksperimen dapat diartikan sebagai metode penelitian yang digunakan untuk mencari pengaruh perlakuan tertentu terhadap yang lain dalam kondisi yang terkendalikan. Penelitian eksperimen menggunakan suatu percobaan yang dirancang secara khusus guna membangkitkan data yang diperlukan untuk menjawab pertanyaan penelitian (Margono, 2005).

Metode eksperimen pada penelitian ini digunakan sebagai penerapan dan percobaan dari dasar teori tentang overclock. Di sini akan dilakukan pengujian, pencatatan serta analisa terhadap suatu sistem komputer yang dioverclock, sehingga dapat diperoleh suatu kesimpulan mengenai perubahanperubahan yang terjadi pada sistem.

Pengujian yang akan dilakukan adalah dengan benchmarking dengan beberapa software khusus untuk benchmarking. Dengan dilakukannya pengujian ini diharapkan dapat mengetahui perubahan performa dan kondisi antara sebelum dan sesudah dilakukannya eksperimen overclocking.

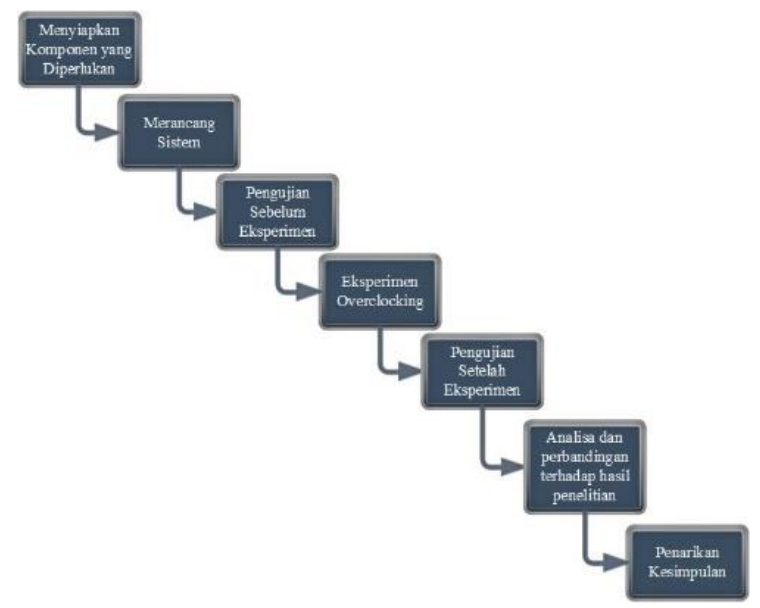




\section{Gambar 2. Rancangan Penelitian}

\subsection{Menyiapkan Komponen Yang Diperlukan}

Komponen yang harus disiapkan untuk melakukan penelitian ini adalah PC (Personal Computer).

\subsection{Merancang Sistem}

Sistem akan dirancang dengan komponen yang telah disiapkan di mana sistem tersebut akan digunakan untuk eksperimen overclocking.

\subsection{Pengujian Sebelum Eksperimen}

Pengujian ini dilakukan sebelum dilakukannya eksperimen overclocking. Pengujian tersebut akan dilakukan dengan software-software khusus untuk benchmarking.

\subsection{Eksperimen Overclocking}

Penulis melakukan eksperimen overclocking untuk meningkatkan frekuensi clock speed dari processor. Overclocking dapat dilakukan dengan 2 cara, yaitu dengan menggunakan software pada Windows atau melalui BIOS. Pada penelitian ini overclocking dilakukan melalui BIOS pada motherboard yang sudah dilengkapi dengan fitur-fitur khusus untuk overclocking.

\subsection{Pengujian Setelah Eksperimen}

Pengujian ini dilakukan setelah ekperimen overclocking. Pengujian ini dilakukan untuk mengetahui perubahan kondisi dari processor setelah di-overclock.

\subsection{Analisa dan Perbandingan Terhadap Hasil Penelitian}

Setelah melakukan pengujian sebelum dan setelah dilakukannya eksperimen overclocking, hasil pengujian tersebut akan dibandingkan dan dianalisa untuk memperoleh suatu kesimpulan.

\subsection{Penarikan Kesimpulan}

Dari hasil analisa tersebut akan ditarik suatu kesimpulan yang mana akan meliputi pencapaian dari hasil analisa tersebut

\section{HASIL DAN PEMBAHASAN \\ 4.1 Persiapan Hardware}

Adapun hardware yang digunakan untuk eksperimen yaitu:

1) ASUS P8P67 LGA 1155

2) Intel Core i5-2500k $3,3 \mathrm{GHz}$

3) Cooler Master Hyper 212 LED Dual Fan

4) Samsung $2 \times 4 G B$ DDR3 Dual Channel $1600 \mathrm{MHz}$

5) ASUS Nvidia Geforce GT630 OEM 2GB DDR3 128bit

6) WD $320 G B$

7) Aerocool LUX $550 W$

8) SADES SPHINX Black

\subsection{Persiapan Software}

Adapun beberapa software yang digunakan untuk pengujian dari eksperimen overclocking:

1) AIDA64

2) Cinebench R15

3) Intel Extreme Tuning Utility

4) PCMark 7

5) 3DMark 11

6) HWBOT Prime

7) $\mathrm{CPU}-Z$

8) BootRacer

9) Corel VideoStudio 2018

10) Metro Last Night Redux

\subsection{Eksperimen Overclocking}

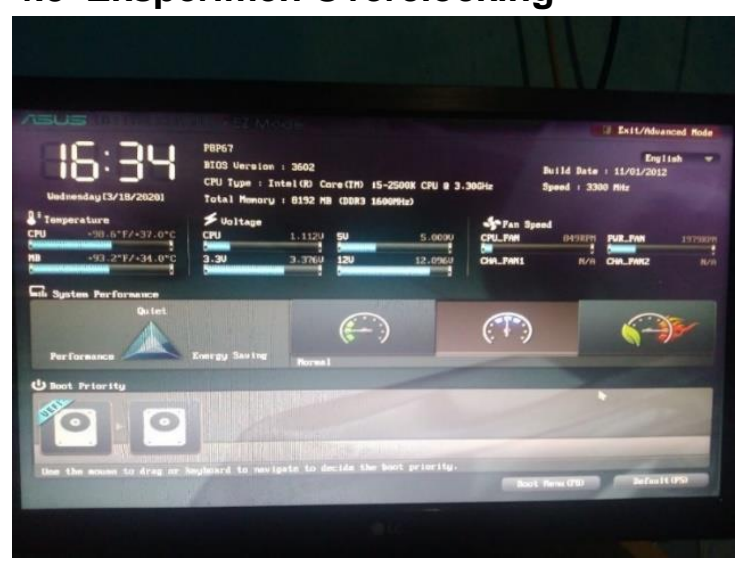

Gambar 2. Tampilan awal menu BIOS 
Eksperimen overclocking dilakukan melalui BIOS pada motherboard yang sudah dilengkapi dengan fitur untuk menaikkan clock speed dan tegangan pada processor. Target clock speed yang ingin dicapai adalah hingga $4,5 \mathrm{GHz}$. Rumus dalam overclocking adalah seperti ini

Clock Speed $=$ BCLK $x$ Multiplier

Langkah-langkah overclocking:

1) Untuk masuk ke menu BIOS, tekan tombol "Delete" pada keyboard ketika komputer baru menyala. Sebelumnya akan diarahkan ke mode EZ dari BIOS tersebut yangmana mode tersebut terdapat informasi dari komponen yang digunakan serta pengaturan performa otomatis untuk processor. Arahkan ke halaman Advanced Mode untuk pengaturan selengkapnya. Sebelum memberikan pengaturan overclock, reset semua pengaturan pada BIOS ke pengaturan semula dengan menekan tombol F5 pada keyboard.

2) Konfigurasi Ai Tweaker ini meliputi mengatur Bus Clock dan Multiplier, konfigurasi DIGI+ Power Control, dan mengatur tegangan. Supaya bisa mengatur angka-angka untuk Bus Clock dan Multiplier, Al Overclock Tuner harus diubah ke Manual. Frekuensi Bus Clock (BCLK) diatur ke $100 \mathrm{MHz}$ (default). Turbo Ratio harus diatur untuk semua core dan masukkan angka multiplier 45. Memory Frequency disesuaikan dengan RAM yang digunakan (DDR3-1600MHz).

3) DIGI+ Power Control adalah sebuah pengaturan pada BIOS yang menawarkan memori ultra-presisi dan tuning tegangan untuk efisiensi sistem, stabilitas, dan kinerja yang optimal.

4) Pilih tab Advanced kemudian pilih menu CPU Configuration. Atur ke pengaturan Disable untuk CPU C1E, CPU C3 Report, dan CPU C6 Report. Arahkan ke tab Monitor kemudian nonaktifkan Q-Fan Control pada CPU dan Chassis.

5) Setelah melakukan beberapa konfigurasi, simpan semua pengaturan dengan menekan tombol F10 pada keyboard kemudian pilih Yes. Maka sistem komputer akan restart secara otomatis.

\subsection{Perbandingan Kondisi Processor Dengan Stress Test}

Tabel 1. Perbandingan hasil Stress Test

\begin{tabular}{cccc}
\hline $\begin{array}{c}\text { Pengu } \\
\text { jian }\end{array}$ & $\begin{array}{c}\text { Default } \\
(3,3 \mathrm{GHz})\end{array}$ & $\begin{array}{c}\text { Over } \\
\text { clock } \\
(\mathbf{4}, 5 \mathrm{GHz})\end{array}$ & $\begin{array}{c}\text { Peru } \\
\text { bahan }\end{array}$ \\
\hline $\begin{array}{c}\text { CPU } \\
\text { Core }\end{array}$ & $50-55$ & $75-80$ & $45,45 \%$ \\
$\begin{array}{c}\text { Temp } \\
\text { (Celsius) } \\
\text { CPU }\end{array}$ & & & \\
$\begin{array}{c}\text { Voltage } \\
\text { (Volt) } \\
\text { CPU }\end{array}$ & $1,100-$ & $1,35-1,36$ & $17,24 \%$ \\
$\begin{array}{c}\text { Power } \\
\text { (Watt) }\end{array}$ & $50-55,7$ & $90-100$ & $79,53 \%$ \\
\hline
\end{tabular}

\subsection{Perbandingan Hasil Benchmarking}

Tabel 2. Perbandingan hasil Benchmarking

\begin{tabular}{|c|c|c|c|c|c|}
\hline No. & $\begin{array}{c}\text { Softwa } \\
\text { re }\end{array}$ & $\begin{array}{c}\text { Pengujia } \\
\mathbf{n}\end{array}$ & $\begin{array}{c}\text { Defaul } \\
t \\
(3,3 \mathrm{G} \\
\mathrm{Hz})\end{array}$ & $\begin{array}{c}\text { Over } \\
\text { clock } \\
(4,5 \mathrm{GH} \\
\text { z) }\end{array}$ & $\begin{array}{c}\text { Kenai } \\
\text { kan } \\
\text { Kiner } \\
\text { ja (\%) }\end{array}$ \\
\hline \multirow{14}{*}{1.} & \multirow{14}{*}{ AIDA64 } & CPU & 31546 & 42864 & $\begin{array}{c}35,88 \\
\%\end{array}$ \\
\hline & & CPU & & & - \\
\hline & & $\begin{array}{c}\text { Photowor } \\
x x\end{array}$ & 7775 & $\begin{array}{c}7 / 30,6 \\
7\end{array}$ & $\begin{array}{c}0,57 \\
\%\end{array}$ \\
\hline & & & 203,56 & & 35,69 \\
\hline & & CPU ZLib & 7 & 276,23 & $\%$ \\
\hline & & CPU AES & $\begin{array}{c}11451 \\
3\end{array}$ & 15570 & $\begin{array}{c}35,97 \\
\%\end{array}$ \\
\hline & & CPU & 681 & 926 & 35,98 \\
\hline & & SHA3 & & 926 & $\%$ \\
\hline & & FPU Julia & 16244 & $\begin{array}{c}21691 \\
33\end{array}$ & $\begin{array}{c}33,53 \\
\%\end{array}$ \\
\hline & & FPU & 9039,6 & 11721 & 29,66 \\
\hline & & Mandel & 7 & 11721 & $\%$ \\
\hline & & FPU & 2925 & 3977 & 35,97 \\
\hline & & SinJulia & & & $\%$ \\
\hline & & FP32 & 2841,6 & 3904,6 & 37,41 \\
\hline
\end{tabular}




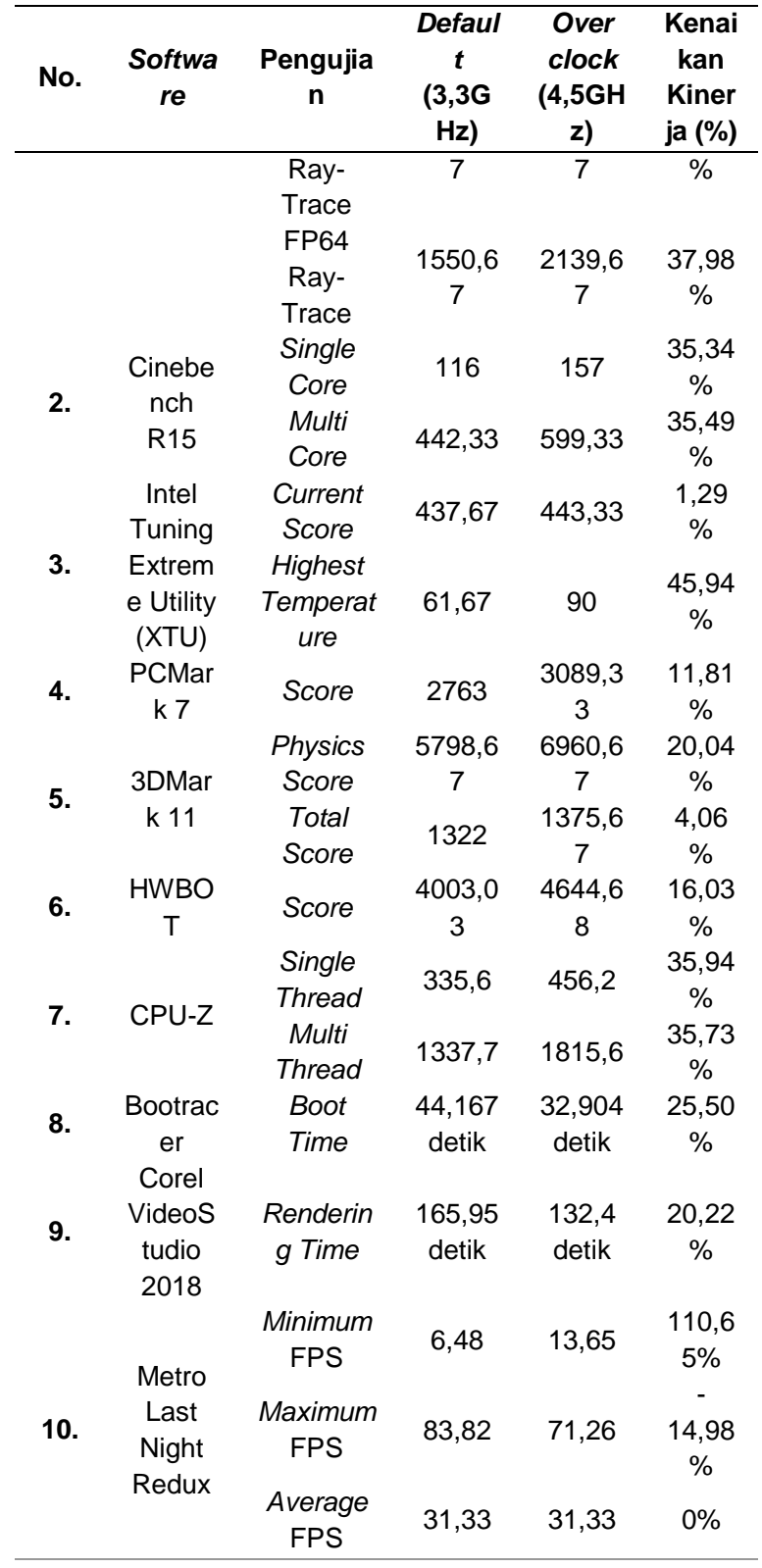

\subsection{Analisis Hasil}

Dari perbandingan di atas dapat diperoleh hasil analisa:

1) Pada hasil AIDA64 stress test, dapat diketahui bahwa terjadi perubahan suhu, tegangan, dan daya yang cukup signifikan. Diketahui suhu processor setelah di-overclock adalah 75-80 Celsius. Suhu tersebut terbilang sudah overheat tapi masih dalam batas toleransi suhu processor karena Tjunction Max pada processor Intel i52500k adalah 98 Celsius.
2) Pada hasil AIDA64 benchmark, peningkatan kinerja pada CPU sudah sesuai dengan harapan, kecuali CPU Photoworxx yang mengalami penurunan kinerja.

3) Peningkatan kinerja yang signifikan ditunjukkan pada skor Cinebench R15, Intel XTU, PCMark 7, 3DMark 11, HWBOT, CPU-Z, BootRacer dan Corel VideoStudio 2018.

4) Pada hasil XTU, dapat dilihat bahwa peningkatan suhu pada processor berbeda dengan ketika stress test menggunakan AIDA64. Hal ini dikarenakan metode yang digunakan oleh XTU lebih memaksa dan menyiksa hingga dapat memperoleh hasil yang maksimal.

5) Hasil BootRacer dan Corel VideoStudio 2018 ditunjukkan dengan adanya peningkatan kecepatan pemrosesan.

6) Kenaikan kinerja pada game Metro Last Night Redux tidak terlalu signifikan karena yang mempengaruhi kenaikan kinerja pada game adalah kinerja VGA card, sedangkan overclocking processor tidak mempengaruhi kinerja VGA card.

\section{KESIMPULAN DAN SARAN}

\subsection{KESIMPULAN}

Dari hasil analisis pada pengujian yang telah dilakukan dapat diperoleh kesimpulan bahwa hasil yang dilakukan pada hampir semua software untuk benchmarking menunjukkan peningkatan kinerja yang cukup signifikan dan dapat meningkatkan kecepatan pemrosesan ketika melakukan booting OS dan rendering. Pada AIDA64 peningkatan kinerja terlihat ketika melakukan benchmark dengan beberapa metode kecuali metode CPU Photoworxx yang mengalami penurunan. Overclocking 
processor tidak terlalu mempengaruhi kinerja pada game Metro 2033 Redux karena tentunya yang mempengaruhi kinerja pada game adalah VGA card. Overclocking pada processor dapat mempengaruhi kenaikan suhu hingga overheat walaupun masih dalam batas toleransi suhu processor. Overclocking juga mempengaruhi peningkatan konsumsi daya yang diperlukan.

\subsection{SARAN}

Setelah melakukan penelitian, penulis ingin menyampaikan saran untuk penelitian selanjutnya. Adapun sarannya adalah sebagai berikut:

1) Untuk menjaga suhu processor agar tetap berada pada batas aman suhu, sebaiknya menggunakan water cooler untuk menjaga suhu processor.

2) Sebaiknya untuk eksperimen overclocking selanjutnya menggunakan processor generasi terbaru yang menggunakan teknologi terbaru untuk menjaga kestabilan kinerja processor.

3) Sebaiknya menggunakan VGA card kelas high-end untuk kinerja yang lebih optimal.

\section{DAFTAR PUSTAKA}

Azhar, A. and H, F., 2019. Analisis Kinerja Prosesor terhadap Proses Overclocking dan Downclocking. Ainet: Jurnal Informatika, 1(1), pp.712.

Fahrizal, R., Alfanz, R. and Sakti, A., 2016. Analysis of effect overclocking durability on Intel processor i5 4670K. In: Proceedings of 2016 4th International Conference on Cyber and IT Service Management, CITSM 2016.

Indriyatmoko, T. and Arief, M.R., 2015. ANALISIS PENGARUH OVERCLOCKING TERHADAP KINERJA SISTEM DALAM MELAKUKAN RENDERING. STMIK
AMIKOM YOGYAKARTA, 151, pp.10-17.

Lutfi, M. and Prasetyo, H., 2017. Analisis Kinerja Overclock Processor Intel Core 17 2600K Pada Chipset Motherboard P67. Jurnal Transformasi, 12(1), pp.17-23.

Margono, S., 2005. Metodologi Penelitian Pendidikan. Jakarta: Rineka Cipta.

Nurrachma, M.M. and Syafrizal, M., 2016. ANALISIS OVERCLOCKING PADA PC DESKTOP DAN PEMBUATAN PHASE CHANGE UNTUK SISTEM PENDINGIN PROSESOR. STMIK AMIKOM YOGYAKARTA, 53, pp.1689-1699.

Sari, M.Y., 2014. KOMPONEN PROCESSOR. SEMARANG.

Sedarmayanti, H. and Hidayat, S., 2002. Metodologi penelitian. Bandung: Mandar Maju.

Sugiyono, 2018. Metode Penelitian Kombinasi (mixed Methods). International Journal of Physiology.

Zuriah, N., 2006. Metodologi penelitian sosial dan pendidikan. Jakarta: Bumi Aksara. 